\title{
INFLUENCE OF AGE ON DELAYED SURGICAL TREATMENT OF PROXIMAL FEMORAL FRACTURES
}

\author{
Lisiane Pinto Gomes ${ }^{1}$, Leandra Delfim do Nascimento ${ }^{1}$, Tulio Vinicius de Oliveira Campos ${ }^{2,3}$, Edson Barreto Paiva ${ }^{3}$, \\ Marco Antonio Percope de Andrade ${ }^{2}$, Henrique Cerqueira Guimarães 3
}

\section{ABSTRACT}

Objective: To investigate the influence of patients' age on the delay between diagnosis and surgical treatment of proximal femoral fractures. Methods: This is a retrospective study, conducted at a tertiary university hospital, including all patients admitted with proximal femoral fractures between March 2013 and March 2014. The participants were categorized into four groups according to age levels. The groups were compared according to demographics, comorbidities, fracture type, trauma circumstances, and time between diagnosis and surgical procedure. Results: One hundred and sixty one patients were included, 37 adults and 124 elderly. Among adults, the mean delay between diagnosis and surgical procedure was $6.4 \pm 5.3$ days; among elderly the delay was $9.5 \pm 7.6$ days. There was a progressive increase in the delay from the young-adults group through the elderly individuals (Kruskal-Wallis: 13.7; $p=0.003$ ). Conclusion: In spite of being the patients most susceptible to complications due to surgical delay, the elderly individuals presented the longest delays from admission to surgical treatment.

\section{Level of Evidence III, Retrospective Study.}

Keywords: Hip fractures. Orthopedics. Aged. Comorbidity

Citation: Gomes LP, Nascimento LD, Campos TVO, Paiva EB, Andrade MAP, Guimarães HC. Influence of age on delayed surgical treatment of proximal femoral fractures. Acta Ortop Bras. [online]. 2015;23(6):315-8. Available from URL: http://www.scielo.br/aob.

\section{INTRODUCTION}

Proximal femoral fracture (PFF) is a global level public health issue. ${ }^{1}$ It occurs typically in individuals over the age of 60 , especially in post-menopausal women, ${ }^{2}$ usually due to low-energy trauma such as falls to the ground. ${ }^{3,4}$ However, this type of fracture can also be observed in young patients and, in these cases, it relates to high-energy trauma such as automobile injuries. ${ }^{5,6}$

International recommendations suggest that patients with PFF undergo surgical treatment 24-48h after diagnosis. ${ }^{7}$ The benefit of early intervention seems to be more prominent in the elderly subpopulation considered fragile, to whom the resulting immobility of acute hip fracture can be devastating. ${ }^{8}$ However, it is not uncommon for the elderly individual to be admitted in adverse clinical condition, prone to postponement of surgery. ${ }^{9}$ Few studies have proposed to compare the characteristics of young and elderly patients with PFF. ${ }^{10}$ Moreover, we found no studies which have analyzed the influence of age in the time between hospital admission and surgery.

The Hospital Risoleta Tolentino Neves (HRTN) is a tertiary teaching hospital, associated to the Universidade Federal de Minas Gerais (UFMG) in Belo Horizonte, Brazil, which is responsible for emergency care of patients with traumatic and non-traumatic conditions in the populous northern axis of this metropolitan region. In this institution there are full structural conditions to offer the necessary surgery to correct any type of PFF. We report in this paper the results of a retrospective study that aimed to evaluate the association between age and various characteristics related to the occurrence and treatment of PFF.

\section{METHODS}

A search for patients treated between March 2013 and March 2014, aged over 17 years, admitted under the International Classification of Diseases (ICD) record compatible with proximal femoral fracture (S 72.0, S72.1, 72.2 S, S 72.8 and S 72.9) was performed in the electronic database made available from the Hospital's IT Department. Individuals with PFF admitted with codes different from the above mentioned were screened from the Surgical Center records. The study was approved by the Research Ethics Committee of UFMG on August $20^{\text {th }}, 2014$, under the protocol number 761,898 .

It is worth noticing that in this Hospital the elderly admitted with PFF are daily tracked by an active search engine, and are served by a multidisciplinary orthogeriatrics team. These

All the authors declare that there is no potential conflict of interest referring to this article.

1. Universidade Federal de Minas Gerais, Multi-professional Residency in Elderly Health, Belo Horizonte, MG, Brazil.

2. Universidade Federal de Minas Gerais, Faculdade de Medicina, Department of the Locomotor System, Belo Horizonte, MG, Brazil.

3. Universidade Federal de Minas Gerais, Hospital Risoleta Tolentino Neves, Belo Horizonte, MG, Brazil.

Work developed at Hospital Risoleta Tolentino Neves, Universidade Federal de Minas Gerais, Belo Horizonte, MG, Brazil.

Correspondence: Henrique Cerqueira Guimarães, Av. Contorno, 4747, sala 1710, 30110-921 Belo Horizonte, MG, Brazil. hcerqueirag@gmail.com 
patients were submitted, within the first $24 \mathrm{~h}$ of admission, to a pre-operative clinical assessment in order to provide patients with surgical conditions as early as possible. Moreover, throughout the hospitalization period, these patients undergo a comprehensive geriatric assessment, dedicated to determine patients functional, neuropsychiatric, cognitive and motor aspects, which allow the identification of factors and mechanisms associated with the occurrence of trauma in each individual. Information concerning sociodemographic characteristics, circumstances and characteristics of trauma, and clinical and neuropsychiatric comorbidities was obtained through a structured collection instrument. The documented outcomes were: time elapsed between hospital admission and surgery, percentage of cases solved within the institution, and in-hospital mortality rates.

\section{Statistical analysis}

Patients were grouped according to age: Group I, adults aged 18-59 years, Group II, patients aged over 60 years. Group I was divided into Group A, formed by young adults aged 18-39 years, and Group B, represented by mature adults aged 40-59 years. The seniors group was subdivided into Group C, elderly aged 60-79 years, and Group D, elderly aged over 79 years old (very elderly).

Categorical variables were presented as proportions, and continuous variables as mean \pm standard deviation. According to Kolmogorov-Smirnov test a non-parametric distribution was observed for continuous variables. The groups were compared, therefore, through the chi-square tests for categorical variables and Kruskal-Wallis test for continuous ones. A value of $p \leq 0.05$ was considered statistically significant.

\section{RESULTS}

A total of 161 patients diagnosed with PFF were included in this study. Thirty-seven patients $(22.98 \%)$ were aged between 18 and 59 years (adults). Of these, eleven (6.83\%) belonged to group A, and twenty-six (16.41\%) to group B. One hundred and twenty-four patients $(77.01 \%)$ were older than 59 years (seniors) being forty-eight (29.81\%) on group C and seventy-six (47.20\%) on group D.

Table 1 shows the characteristics of the groups according to their distribution by gender, and types of fracture. There was a clear predominance of women in the elderly group $(64.51 \%$ vs. $24.32 \%$, p <0.0001). This phenomenon is even more pronounced in the group aged 79 years or older (very elderly) as compared to group C (72.36\% vs. $52.08 \%$; $p=0.035)$. We identified no difference in gender distribution between adults' subgroups, in which there was a male predominance. In the adults' group there was a higher incidence of femoral neck fractures compared to the elderly group (51.35\% vs. $31.45 \%$, $\mathrm{p}=0.044$ ), which showed a predominance of trochanteric fractures (62.09 vs. $35.13 \%, p=0.007$ ).

Table 2 shows the causes of trauma. There was a higher frequency of traffic accidents in the adults' group as compared to the elderly group $(29.72 \%$ vs. $2.41 \%, p<0.0001)$. From the age of 40 years on, fall to the ground becomes the most prevalent cause.

Table 3 shows the profile of comorbidities observed. The percentage of victims who did not have any comorbidity was higher in the adult group (67.56\% vs. $7.25 \%, p<0.0001)$, whereas multiple clinical comorbidities were observed more frequently in the elderly group (13.51\% vs. $75 \%$; $p<0.0001)$. Parkinsonism syndrome was found in $33.87 \%$ of the elderly. Additionally, dementia was reported in $49.19 \%$ of patients in this group, and was especially prevalent in group $\mathrm{D}$ as compared to group $\mathrm{C}$ (73.77\% vs. 26.02\%; $p=0.009$ ). It should be noticed, however, that adults received no formal geriatric assessment, i.e. were not submitted to motor and cognitive assessment.

As for the outcomes of the cases shown in Table 4, there were no differences regarding in-hospital mortality between groups. It is Important, however, to notice that a significant percent-

\begin{tabular}{l} 
Table 1. Distribution by gender and type of fracture. \\
\hline \\
\hline
\end{tabular}

Table 2. Characteristics of groups regarding causes of trauma

\begin{tabular}{|c|c|c|c|c|c|c|}
\hline & \multicolumn{3}{|c|}{ Adults } & \multicolumn{3}{|c|}{ Elderly } \\
\hline & Total & \begin{tabular}{|c|} 
Group A \\
$18-39$ \\
years old
\end{tabular} & $\begin{array}{c}\text { Group B } \\
40-59 \\
\text { years old } \\
\end{array}$ & Total & $\begin{array}{l}\text { Group C } \\
60-79 \\
\text { years old }\end{array}$ & $\begin{array}{c}\text { Group D } \\
>79 \text { years } \\
\text { old }\end{array}$ \\
\hline Traffic accident $^{c}$ & $29,72 \%$ & $45,45 \%$ & $23,07 \%$ & $2,41 \%$ & $6,25 \%$ & 0 \\
\hline Interpersonal violence & $2,70 \%$ & $9,09 \%$ & 0 & $0,80 \%$ & $2,08 \%$ & 0 \\
\hline Fall to the ground $\mathrm{a}^{\mathrm{a}, \mathrm{c}}$ & $56,75 \%$ & $27,27 \%$ & $69,23 \%$ & $84,67 \%$ & $77,08 \%$ & $89,40 \%$ \\
\hline $\begin{array}{l}\text { Clinical } \\
\text { decompensation * }\end{array}$ & $2,70 \%$ & $9,09 \%$ & 0 & $4,03 \%$ & 0 & $6,57 \%$ \\
\hline Risk behavior ** & $8,10 \%$ & $9,09 \%$ & $7,69 \%$ & $6,45 \%$ & $12,50 \%$ & $2,63 \%$ \\
\hline No trauma & 0 & 0 & 0 & $1,61 \%$ & 2,08 & $1,31 \%$ \\
\hline
\end{tabular}

\begin{tabular}{l} 
Table 3. Comorbidity profile. \\
\hline
\end{tabular}

Table 4. Hospital outcomes

\begin{tabular}{|c|c|c|c|c|c|c|}
\hline & \multirow[b]{2}{*}{$\begin{array}{l}\text { Total } \\
\mathrm{N}=37\end{array}$} & \multirow[b]{2}{*}{\begin{tabular}{|c|} 
Group A \\
$18-39$ \\
years old
\end{tabular}} & \multirow[b]{2}{*}{$\begin{array}{c}\text { Group B } \\
40-59 \\
\text { years old }\end{array}$} & \multirow[b]{2}{*}{ Total } & \multirow[b]{2}{*}{$\begin{array}{c}\text { Group C } \\
60-79 \\
\text { years old }\end{array}$} & \multirow[b]{2}{*}{$\begin{array}{c}\text { Group D } \\
>79 \text { years } \\
\text { old }\end{array}$} \\
\hline & & & & & & \\
\hline Discharge $^{b . c}$ & $86.48 \%$ & $81.80 \%$ & $88.46 \%$ & $56.45 \%$ & $70.33 \%$ & $47.36 \%$ \\
\hline Transference b.c & $10.81 \%$ & $9.09 \%$ & $11.53 \%$ & $34.67 \%$ & $22.91 \%$ & $42.10 \%$ \\
\hline Death & 0 & 0 & 0 & $8.06 \%$ & $6.25 \%$ & $9.21 \%$ \\
\hline No records & $2.70 \%$ & $9.09 \%$ & 0 & $0.80 \%$ & 0 & $1.31 \%$ \\
\hline
\end{tabular}


age of participants were transferred to other institutions for surgery, according to the healthcare network functioning of the city of Belo Horizonte. This outcome was more frequently observed in the elderly group (34.67\% vs. $10.81 \% ; p=0.009$ ), especially in group $D$ as compared to group C (42.10\% vs. $22.91 \% \mathrm{p}=0.046$ ).

Figure 1 shows the distribution of time intervals (days) between hospital admission and surgical treatment of PFF among the four age groups. There was a clear progression in this interval according to age increase: group A, 3.88 \pm 4.51 days; group $B, 7.63 \pm 5.32$ days; group C, $7.87 \pm 7.49$ days; and group $D$, $10.97 \pm 7.44$ days (Kruskal-Wallis $=13.7, p=0.003$ ). A post-hoc analysis between groups showed statistically significant differences $(p<0.05)$ between the elderly (group $D$ ), and participants in the groups $C$ and $A$. The comparison between group $D$ and $B$ has not reached the threshold of statistical significance.

The disparate difference between elderly and adults regarding the delay observed between admission and surgery, we analyzed the causes related to non-compliance of the proposed surgical planning among the different age groups (Table 5). The number of failures to perform surgery was significantly more frequent among the elderly compared to adults $(59.99 \%$ vs. $27.03 \% ; p=0.0007$ ), especially in the group of older individuals $(71.42 \%$ vs. $41.18 \% ; p=0.001)$. It is worth pointing out that some participants experienced changes on surgical plans more than once. Although not undergoing surgery for lack of medical condition or death was more frequently observed in the group of very elderly $(10.71 \%$ vs. $0 \% ; p=0.007)$, this situation justified not performing surgery in only $11.11 \%$ of cases. The leading cause of non-compliance with surgical proposal was represented by logistical shortcomings in planning and

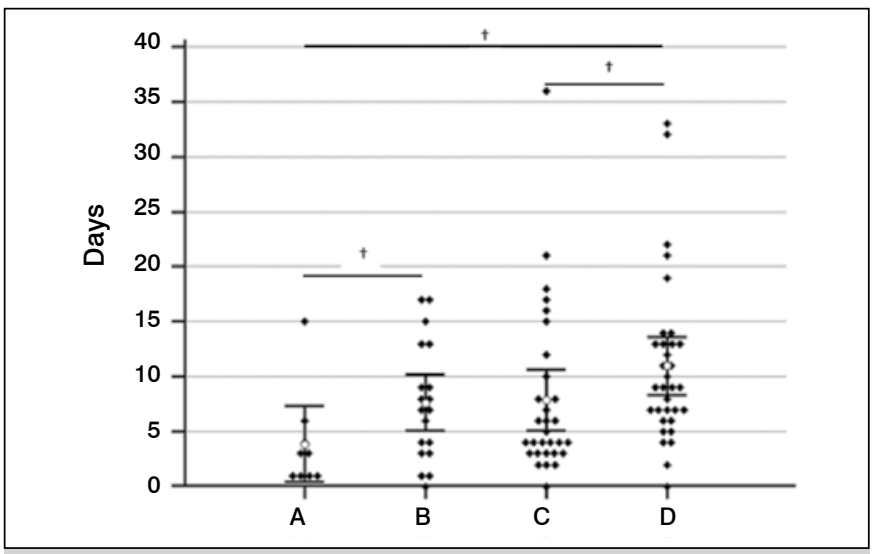

Figure 1. Time lapse between hospital admission by PFF and its surgical correction according to the age groups studied (Kruskal-Wallis $=13.7$, $p=0.003 ; p<0.05)$

Table 5. Surgical planning

\begin{tabular}{|c|c|c|c|c|}
\hline & Adults & & Elderly & \\
\hline & $\begin{array}{l}\text { Total } \\
n=37\end{array}$ & $\begin{array}{c}\text { Total } \\
n=135\end{array}$ & \begin{tabular}{|c|} 
Group C \\
$60-79^{\text {years old }}$ \\
\end{tabular} & \begin{tabular}{|l} 
Group D \\
$>79$ years old
\end{tabular} \\
\hline Effective surgery performed ${ }^{\text {a.b.c }}$ & $67.57 \%$ & $31.11 \%$ & $47.06 \%$ & $21.43 \%$ \\
\hline Conservative treatment proposal & $5.40 \%$ & $8.90 \%$ & $11.76 \%$ & $7.15 \%$ \\
\hline Not performed & $27.03 \%$ & $59.99 \%$ & $41.18 \%$ & $71.42 \%$ \\
\hline$>$ No clinical condition/death ${ }^{\text {a.b }}$ & $0.0 \%$ & $6.66 \%$ & $0.0 \%$ & $10.71 \%$ \\
\hline$>$ Logistics deficiency $^{*}$ a.b.c & $27.03 \%$ & $53.33 \%$ & $41.18 \%$ & $60.71 \%$ \\
\hline
\end{tabular}

realization of the surgery, as calendar outages within a reasonable time, unavailability of operating room on the scheduled day, insufficient anesthetists, lack of bed in intensive care unit (ICU) for the postoperative care, or lack of appropriate equipment for the surgery. This situation was observed in $53.33 \%$ of cases in the elderly group compared with $27.03 \%$ in the adult group ( $p=0.003$ ), and was especially frequent in the very elderly $(60.71 \%$ vs. $41.18 \% ; p=0.04)$. It is noteworthy that the unavailability of ICU beds represented only $5.55 \%$ of the causes of non-surgical realization among the elderly.

\section{DISCUSSION}

The results showed that the PFF was more prevalent among the elderly, including a remarkable difference in gender distribution according to age, with a higher participation of men in the adult group and the opposite in the elderly. There were more traffic accidents and femoral neck fracture in the group of young adults, while in the other groups the most frequent cause of trauma was represented by falling to the ground, and the most observed type of fracture was trochanteric. Moreover, through extensive geriatric assessment, it was possible to identify a significant number of elderly people with neurodegenerative conditions, such as parkinsonism and dementia. The main finding of the study, however, concerns the low surgical treatment efficiency in cases of elderly participants, characterized by a high transfer rate to other institutions and an unacceptable time delay between admission and surgery, considering the international recommendations for treating PFF.

Dissociation regarding gender distribution had been already described in a comparative study of trauma in the elderly and non-elderly at a teaching hospital of Curitiba, Brazil. ${ }^{5}$ The predominance of car accidents as a cause of trauma in very young people corroborates the impression on the association between masculine gender and greater exposure to risky activities. The predominance of women in the elderly group, and especially in the very elderly, is a highly replicated finding in the literature ${ }^{6}$ and evokes various aspects related to female aging, such as longer life span, higher prevalence of osteoporosis, dementia and disabilities. ${ }^{11}$

There was an increase in the frequency of falls to the ground with advancing age. Moreover, this mechanism was the main cause of fracture in all groups except in the group of young adults, a phenomenon reported in national and international studies on the topic. ${ }^{12,13}$ It is noteworthy the frequency of falls to the ground in adults aged over 40 . This result is in agreement with a study which assessed the demographic characteristics of victims of falls to the ground, where it was observed that $67.86 \%$ of patients were younger than 60 years, ${ }^{14}$ and reinforce the recommendation of a comprehensive geriatric assessment for those affected by PFF also in this age group.

The multidisciplinary evaluation strategy under geriatric medical orientation allowed the identification of dementia in $49.19 \%$ of elderly individuals, and parkinsonism in $33.87 \%$ of patients in this group. It is noteworthy that these figures were even more significant in the very elderly subgroup, in which dementia was observed in $73.77 \%$ and parkinsonism in $40.78 \%$ of participants. This binomial, cognitive impairment and motor disability, can be devastating to maintain a safe posture stability. Dementia causes impairment in several cognitive functions, and often compromi- 
ses patients' critical judgment, motivating him/her to engage in activities for which he/she no longer meets the ability to execute safely. ${ }^{15}$ The incidence of parkinsonism increases remarkably with aging. ${ }^{16}$ Postural control, played by midbrain structures, is frequently affected in these individuals, and may be severely compromised, ${ }^{17}$ especially when combined with the cognitive manifestations of dementia. Importantly, the identification of these conditions is an essential step for planning rehabilitative measures and those aimed at preventing future falls.

In the adults group, the average time between admission and surgery was $6.42 \pm 5.3$ days, and in the elderly group, 9.46 \pm 7.56 days. This result is in agreement with another national study, which included elderly aged 60-104 years, in which the mean time observed between admission and surgery was 9.35 \pm 7.48 days. ${ }^{18}$ However, there is a clear non-compliance with international recommendations on the optimal time for surgical treatment of PFF, which postulate a maximum window of $48 \mathrm{~h}$ between diagnosis and therapeutic intervention. ${ }^{7}$ As noted, this situation is not unique to the service reported here and can be observed in other Brazilian university hospitals with similar characteristics as HRTN, suggesting that this is a commonplace phenomenon in our country.

In the comparison between groups, it was observed that the resolution of cases was significantly higher in the group of adult patients at the expense of the elderly, and that the interval between admission and surgical treatment increased steadily over the four age groups. This finding is worrying since the elderly constitute the group most injured by the postponement of surgery. ${ }^{8}$ The main reason for patient transfer was related to the cancellation of surgery because of non-clinical reasons. The waiting time between admission and surgical scheduling was usually sufficient for most of the adverse clinical conditions to be circumvented. In fact, solving cases of young adults, markedly in higher number than the elderly's, points to weak institutional mechanisms to prioritize cases. The Association of Anesthetists of Great Britain and Ireland recommends the establishment of a specific trauma list for patients with hip fracture, priority based, including weekends and holidays, separately from the other surgical lists, besides non random allocation of anesthesiologist, given the complexity of these patients and the possibility of borderline clinical condition at the time of surgery. ${ }^{19}$ It should be noted that both recommendations are not followed by the institution where our data were collected.

Finally, it is important to point out the limitations of this study. Its retrospective nature limits the quality of the information obtained, especially regarding the details of the circumstances of trauma, which in many cases could not be rescued. The fact that only the elderly were subjected to formal geriatric assessment also limits the characterization of comorbidities in the group aged over 40 years, in which falls to the ground was the leading cause of trauma. It is possible that neurodegenerative conditions could also be found in these participants through specific diagnostic evaluation, contributing to the understanding of the causes of fall in this group. Finally, as a significant percentage of the elderly participants were transferred to surgical treatment in other institutions, the analysis of mortality as an outcome is impaired in this study.

\section{CONCLUSION}

We identified relevant differences between the age groups and various characteristics related to PFF. However, the therapeutic delay observed in the frailer group of patients was the most salient and disturbing aspect of this work. Despite the fact that our institution relies on physical, personnel and equipment structure for the expeditious correction of PFF, these findings point to the need for institutional mechanisms for prioritizing this profile of patients, according to established international recommendations.

\section{REFERENCES}

1. Sakaki MH, Oliveira AR, Coelho FF, Leme LEG, Suzuki I, Amatuzzi MM. Estudo da mortalidade na fratura do fêmur proximal em idosos Acta Ortop Bras. 2004;12(4):242-9.

2. Rocha MA, Carvalho WS, Zanqueta C, Lemos SC. Estudo epidemiológico retrospectivo das fraturas do fêmur proximal tratados no Hospital Escola da Faculdade de Medicina do Triângulo Mineiro. Rev Bras Ortop. 2001;36(8):311-6.

3. Hungria Neto JS, Dias CR, Almeida JDB. Características epidemiológicas e causas da fratura do terço proximal do fêmur em idosos. Rev Bras Ortop. 2011;46(6):660-7.

4. Carvalho MI. Osteoporose: visão do ortopedista. Rev Bras Ortop. 2006;41(4):91-7.

5. Broska Junior CA, Folchini AB de, Ruediger RRde. Estudo comparativo entre o trauma em idosos e não idosos atendidos em um Hospital Universitário de Curitiba Rev Col Bras Cir. 2013;13(3):281-6.

6. Parreira JG, Soldá SC, Perlingeiro JAG, Padovese CC, Karakhanian WZ, Assef JC. Análise comparativa das características do trauma entre pacientes idosos e não idosos. Rev Assoc Med Bras. 2010;56(5):541-6.

7. National Institute for Health and Clinical Excellence. Hip fracture: the management of hip fracture in adults. Clinical guideline 124. London, UK; National Institute for Health and Clinical Excellence; 2011.

8. Pioli G, Lauretani F, Davoli ML, Martini E, Frondini C, Pellicciotti F, et al. Older people with hip fracture and IADL disability require earlier surgery. J Gerontol A Biol Sci Med Sci. 2012;67(11):1272-7.

9. Patel NK, Sarraf KM, Joseph S, Lee C, Middleton FR. Implementing the National Hip Fracture Database. An audit of care. Injury. 2013;44(12):1934-9.

10. Bennett KM, Scarborough JE, Vaslef S. Outcomes and health care resource utilization in super-elderly trauma patients. J Surg Res. 2010;163(1):127-31.

11. Rizzuto D, Bellocco R, Kivipelto M, Clerici F, Wimo A, Fratiglioni L. Dementia after age 75: survival in different severity stages and years of life lost. Curr Alzheimer Res. 2012;9(7):795-800.

12. Lima RS, Campos ML. Profile of the elderly trauma victims assisted at an Emergency Unit. Rev Esc Enferm USP. 2011;45(3):659-64.

13. Löfman O, Berglund K, Larsson L, Toss G. Changes in hip fracture epidemiology: redistribution between ages, genders and fracture types. Osteoporos Int. 2002;13(1):18-25.

14. Parreira JG, Vianna AM, Cardoso GS, Karakhanian WZ, Calil D, Perlingeiro $\mathrm{JA}$, et al. Severe injuries from falls on the same level. Rev Assoc Med Bras. 2010;56(6):660-4.

15. Carvalho Ade M, Coutinho Eda S. Dementia as risk factor for severe bone fractures among the elderly. Rev Saude Publica. 2002;36(4):448-54.

16. Bennett DA, Beckett LA, Murray AM, Shannon KM, Goetz CG, Pilgrim DM, et al. Prevalence of parkinsonian signs and associated mortality in a community population of older people. N Engl J Med. 1996;334(2):71-6.

17. Jenkinson N, Nandi D, Muthusamy K, Ray NJ, Gregory R, Stein JF, et al. Anatomy, physiology, and pathophysiology of the pedunculopontine nucleus. Mov Disord. 2009;24(3):319-28.

18. Loures, B. Custo- Utilidade do tratamento cirúrgico da fratura do fêmur proximal em idosos, com foco no tempo entre o trauma e o tratamento [dissertação]. Juiz de Fora, MG: Universidade Federal de Juíz de Fora; 2013.

19. Griffiths R, Alper J, Beckingsale A, Goldhill D, Heyburn G, Holloway J, et al. Management of proximal femoral fractures 2011: Association of Anaesthetists of Great Britain and Ireland. Anaesthesia. 2012;67(1):85-98. 